\title{
Association of the IL6 polymorphism rs1800796 with cancer risk: a meta-analysis
}

\author{
Y. Du ${ }^{1,2 *}$, L. Gao ${ }^{1,2 *}$, K. Zhang ${ }^{1}$ and J. Wang ${ }^{1}$ \\ ${ }^{1}$ Key Laboratory of Mental Health, Institute of Psychology, \\ Chinese Academy of Sciences, Beijing, China \\ ${ }^{2}$ University of Chinese Academy of Sciences, Beijing, China \\ *These authors contributed equally to this study. \\ Corresponding authors: J. Wang / K. Zhang \\ E-mail: wangjing@psych.ac.cn / zhangkl@psych.ac.cn
}

Genet. Mol. Res. 14 (4): 13236-13246 (2015)

Received May 5, 2015

Accepted August 21, 2015

Published October 26, 2015

DOI http://dx.doi.org/10.4238/2015.October.26.20

ABSTRACT. The human IL6 [interleukin 6 (interferon, beta 2)] gene encodes IL-6, a cytokine which not only plays regulatory roles in inflammation, but may be also involved in the progression of cancer. Rs 1800796 is a single nucleotide polymorphism (SNP) in the promoter region of $I L 6$, and is associated with IL-6 production. A number of studies have been carried out to determine whether this SNP is associated with cancer risk. However, the results are inconsistent due to small sample sizes of individual studies and limited statistical power. Therefore, to evaluate the overall effect on all investigated cancer types, we conducted a meta-analysis by combining all available studies. Nineteen eligible case-control studies including 23,030 subjects $(9,985$ cases and 13,045 controls) were included for this meta-analysis. Our study demonstrates that rs1800796 is significantly associated with cancer risk in three genetic models (allele $\mathrm{G}$ vs allele $\mathrm{C}$, pooled $\mathrm{OR}=1.182$, $P=0.009 ; C G+G G$ vs $C C$, pooled $O R=1.333, P=0.006 ; C G$ vs $C C$, pooled $O R=1.323, P=0.007)$. Our meta-analysis suggests that 
polymorphism rs1800796 within the IL6 gene may be a potential risk factor for cancer.

Key words: rs1800796; Interleukin 6; Cancer risk; Meta-analysis

\section{INTRODUCTION}

Inflammation is a fundamental innate immune response that arises due to perturbed tissue homeostasis. There is accumulating evidence which suggest that persistent state of inflammation is associated with progression of cancer (Coussens and Werb, 2002). Cytokines, which are secreted by virtually all immune cells as well as various other nucleated cells, play regulatory roles in the immune response pathways, and are key signaling molecules in inflammation (Lowry, 1993). The relationship between cytokines and cancer has been explored by researchers from various fields. Among those, interleukin-6 (IL-6), which is encoded by the IL6 (interleukin 6) gene, has drawn the attention of researchers. Accumulating evidence demonstrate high serum concentration of IL-6 is correlated with negative clinical prognosis in different types of cancer (Lippitz, 2013).

The human IL6 gene is located on chromosome 7p21, and includes five exons and four introns (Ray et al., 1990). Two single nucleotide polymorphisms (SNPs) on the promoter region of IL6, rs1800795 (-174G/C) and rs1800796 (-572C/G), have been identified to be associated with IL6 production (Fishman et al., 1998). Furthermore, a large number of genetic studies have investigated the association of these two SNPs with risk of cancer. In the case of rs1800795, its association with risk of cancer has been published in a previous meta-analysis (Liu et al., 2012). However, while a number of studies have individually assessed the relationship between rs1800796 (-572G/C, also known as $-634 \mathrm{G} / \mathrm{C}$ ) and different types of cancer, no meta-analysis has been published with a compilation of these studies. In the present study, we have conducted a meta-analysis combing all reports together to offer a conclusive assessment on whether rs1800796 increases the risk of cancer.

\section{MATERIAL AND METHODS}

This meta-analysis was conducted according to the PRISMA statement (Preferred reporting items for systematic reviews and meta-analyses) and the guidelines presented in "Systematic Reviews of Genetic Association Studies" (Moher et al., 2009; Sagoo et al., 2009) including search strategy, selection criteria, data extraction and data analysis.

\section{Literature Search}

The databases PubMed, Elsevier, EMBASE, Web of Knowledge, and Wiley Online Library were searched for all articles with the following search terms: (interleukin 6 OR interleukin-6 OR interleukin6 OR IL-6 OR IL6 OR IL 6) AND (polymorphism OR polymorphisms) AND (cancer OR tumor or carcinoma), last search update: March, 2015. Publication date and publication language were not restricted in our search. Reference lists were examined manually to further identify potentially relevant studies. Published genome-wide association studies (GWAS) on lung cancer (phs000093.v2.p2), breast cancer (phs000147.v1.p1), and prostate cancer (phs000207.v1.p1) were also examined. If more than one article was published by the same author using the same case series, the study with the most individual investigators was included in our meta-analysis. 


\section{Inclusion and Exclusion Criteria}

Abstracts of all citations and retrieved studies were reviewed. Studies meeting the following criteria were included: (1) a case-control design was used; (2) association between rs1800796 and cancer was examined; (3) controls were free of autoimmune or inflammatory diseases; (4) available genotype data were provided. Studies were excluded if one of the following was: (1) Study design was based on family or cohort; (2) Genotype frequency was not reported or provided; (3) There was insufficient information for meta-analysis even after requesting from authors.

\section{Data extraction}

All data were independently extracted by two reviewers according to the inclusion criteria listed above. Disagreements were resolved by discussion between the two reviewers. The following characteristics were collected from each study: first author, year of publication, country of sample, ethnicity, number of cases and controls, cancer type, gender of samples, genotyping methods, as well as study design and genotyping frequencies in both cases and controls. As environmental data was not available in most of the studies, this meta-analysis was conducted based on unadjusted data.

\section{Statistical analysis}

Statistical analysis was conducted using the STATA 11.0 software (Stata Corp LP, College Station, TX, United States). The odds ratio (OR) and 95\% confidence interval ( $\mathrm{Cl}$ ) were estimated for each study in a random-effects model, or in a fixed-effects model. Heterogeneity among studies was examined with $X^{2}$-based $Q$ testing and $l^{2}$ statistics. $P<0.1$ was considered significant for the $X^{2}$-based $Q$ testing, and $l^{2}$ was interpreted as the proportion of total variation contributed by between-study variation (Higgins and Thompson, 2002). If there was significant heterogeneity $(P<$ 0.1 ), a random-effects model (the DerSimonian and Laird method) was selected to pool the data. Otherwise, a fixed-effects model (the Mantel-Haenszel method) was selected to pool the data. Pooled ORs were calculated for allele frequency comparison ( $G$ vs C), recessive model (GG vs $C C+C G)$, dominant model (CG + GG vs CC), co-dominant model of homozygote effect (GG vs CC), and co-dominant model of heterozygote effect (CG vs CC and GG vs CG), respectively. The significance of pooled ORs was determined by Z-test, and $\mathrm{P}<0.05$ was considered statistically significant. Subgroup analyses were also performed based on cancer type, ethnicity, gender, genotyping method, and study design if significant heterogeneity was observed in the metaanalysis.

Hardy-Weinberg Equilibrium (HWE) in the controls was tested by the $\mathrm{X}^{2}$ test for goodness of fit using a previous meta-analysis as reference (Verhagen et al. 2010), and $P<0.01$ was considered as significant deviation from HWE. As deviations from HWE in control subjects may bias the estimates of genetic effects in a meta-analysis (Zintzaras, 2010), sensitivity analysis was conducted by comparing results including studies with significant HWE deviations in control subjects with results excluding these studies. Publication bias was examined with funnel plots, where the presence of publication bias was illustrated in the asymmetric shape of funnel plots (Begg and Mazumdar, 1994). In addition, Egger's tests were also carried with a significance level of 0.05 to further detect publication bias. 


\section{RESULTS}

\section{Characteristics of studies}

A total of 1163 papers were retrieved after the first search. Following our screening procedure, 19 case-control studies fulfilled the inclusion criteria. Genotype information was also checked in three available GWAS databases. However, no additional data was acquired. In total, 9,985 cases and 13,045 controls were included in the analysis. The qualities of studies were considered acceptable for our meta-analysis. A flow chart outlining study selection and reasons for exclusion are presented in Figure 1. The cancer types in the 19 studies included lung cancer (6 studies), prostate cancer (4 studies), gastric cancer (3 studies), colorectal cancer (2 studies), breast cancer (2 studies), esophageal cancer (1 study), and hepatocellular carcinoma (1 study). Among these studies, 12 studies consisted of Asian samples, 5 studies with Caucasian samples, 1 study with both Asian and Caucasian samples, and 1 study with both African and Caucasian samples. The gender breakdown of the studies is as follows: 3 studies were female samples, 6 studies were male samples, and 10 studies were mixed samples. Multiple genotyping methods were used in these studies, including microarray (2 studies), polymerase chain reaction - restriction fragment length polymorphism (PCR-RFLP) (8 studies) and Taqman genotyping (9 studies). Furthermore, 12 studies were hospital-based case-control design while 7 studies were population-based casecontrol design. Characteristics of all studies included in the meta-analysis are presented in Table 1.

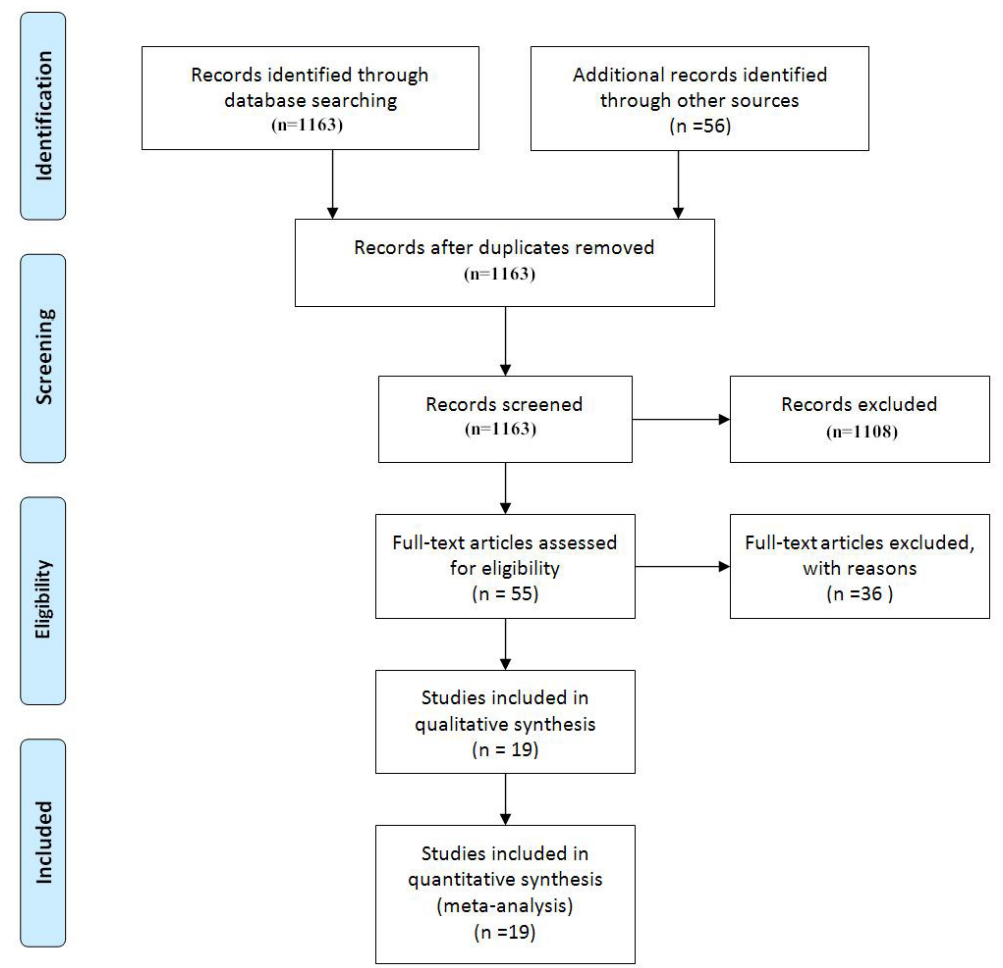

Figure 1. Flow chart of study selection and specific reasons for exclusion. 


\begin{tabular}{|c|c|c|c|c|c|c|c|c|c|c|c|c|c|c|c|}
\hline \multirow[t]{2}{*}{ References } & \multirow[t]{2}{*}{ Cancer type } & \multirow[t]{2}{*}{ Country } & \multirow{2}{*}{$\begin{array}{l}\text { Ethnic } \\
\text { group }\end{array}$} & \multirow{2}{*}{$\begin{array}{l}\text { Genotyping } \\
\text { method }\end{array}$} & \multirow[t]{2}{*}{ Gender } & \multirow{2}{*}{$\begin{array}{l}\text { Study } \\
\text { design }\end{array}$} & \multicolumn{4}{|c|}{$\mathrm{N}$ (Case) } & \multicolumn{4}{|c|}{$\mathrm{N}$ (Control) } & \multirow[t]{2}{*}{ HWE } \\
\hline & & & & & & & Total & $\mathrm{CC}$ & CG & GG & Total & $\mathrm{CC}$ & CG & GG & \\
\hline He et al., (2011) & Breast cancer & China & Asian & PCR-RFLP & Female & $\mathrm{HCC}$ & 176 & 85 & 83 & 8 & 200 & 138 & 59 & 3 & 0.236 \\
\hline Slattery et al., (2008) & Breast cancer & USA & Caucasian & TaqMan & Female & PCC & 1175 & 153 & $1022^{\mathrm{a}}$ & & 1329 & 141 & $1188^{\mathrm{a}}$ & & NA \\
\hline Slattery et al., (2008) & Breast cancer & USA & Mixed & TaqMan & Female & PCC & 575 & 242 & $333^{\mathrm{a}}$ & & 726 & 320 & $406^{a}$ & & NA \\
\hline Tsilidis et al., (2009) & Colorectal cancer & USA & Caucasian & TaqMan & Mixed & PCC & 201 & 2 & 19 & 180 & 362 & 3 & 30 & 329 & 0.019 \\
\hline Slattery et al., (2007) & Colorectal cancer & USA & Caucasian & TaqMan & Mixed & $\mathrm{HCC}$ & 2373 & 27 & 311 & 2035 & 2982 & 34 & 366 & 2582 & $<0.01$ \\
\hline Tang et al., (2007) & Esophageal cancer & China & Asian & PCR-RFLP & Mixed & $\mathrm{HCC}$ & 118 & 74 & 40 & 4 & 130 & 89 & 38 & 3 & 0.652 \\
\hline Hwang et al., (2003) & Gastric cancer & USA & Caucasian & PCR-RFLP & Mixed & $\mathrm{HCC}$ & 30 & 3 & 16 & 11 & 30 & 5 & 7 & 18 & 0.02 \\
\hline Hwang et al., (2003) & Gastric cancer & Mixed & Asian & PCR-RFLP & Mixed & $\mathrm{HCC}$ & 30 & 16 & 13 & 1 & 30 & 16 & 13 & 1 & 0.394 \\
\hline Xing et al., (2006) & Gastric cancer & China & Asian & Microarray & Mixed & PCC & 130 & 4 & 118 & 8 & 142 & 22 & 112 & 8 & $<0.01$ \\
\hline Kang et al., (2009) & Gastric cancer & Korea & Asian & PCR-RFLP & Mixed & PCC & 284 & 154 & 113 & 17 & 278 & 140 & 123 & 15 & 0.069 \\
\hline Bai et al., (2013) & Lung cancer & China & Asian & TaqMan & Mixed & $\mathrm{HCC}$ & 193 & 86 & 89 & 18 & 210 & 125 & 69 & 16 & 0.145 \\
\hline Chen et al., (2013) & Lung cancer & China & Asian & PCR-RFLP & Mixed & $\mathrm{HCC}$ & 1237 & 682 & 474 & 81 & 1252 & 630 & 515 & 107 & 0.904 \\
\hline Liang et al., (2013) & Lung cancer & China & Asian & PCR-RFLP & Mixed & $\mathrm{HCC}$ & 138 & 100 & 29 & 9 & 138 & 105 & 30 & 3 & 0.625 \\
\hline Lim et al., (2011) & Lung cancer & Singapore & Asian & PCR-RFLP & Female & $\mathrm{HCC}$ & 298 & 163 & 123 & 12 & 718 & 449 & 231 & 38 & 0.25 \\
\hline Seow et al., (2006) & Lung cancer & Singapore & Asian & PCR-RFLP & Female & $\mathrm{HCC}$ & 124 & 70 & 46 & 8 & 162 & 97 & 55 & 10 & 0.56 \\
\hline Kiyohara et al., (2014) & Lung cancer & Japan & Asian & TaqMan & Mixed & $\mathrm{HCC}$ & 462 & 259 & 175 & 28 & 379 & 250 & 116 & 13 & 0.919 \\
\hline Sun et al., (2004) & Prostate cancer & Sweden & Caucasian & Microarray & Male & PCC & 1337 & 2 & 109 & 1226 & 753 & 4 & 74 & 675 & 0.211 \\
\hline Bao et al., (2008) & Prostate cancer & China & Asian & TaqMan & Male & $\mathrm{HCC}$ & 136 & 50 & 39 & 47 & 120 & 65 & 27 & 28 & $<0.01$ \\
\hline Pierce et al., (2009) & Prostate cancer & USA & Caucasian & TaqMan & Male & PCC & 175 & 0 & 19 & 156 & 1934 & 2 & 192 & 1740 & 0.161 \\
\hline Pierce et al., (2009) & Prostate cancer & USA & African & TaqMan & Male & PCC & 40 & 1 & 2 & 37 & 300 & 1 & 46 & 253 & 0.47 \\
\hline Wang et al., (2009) & Prostate cancer & USA & Caucasian & TaqMan & Male & PCC & 253 & 1 & 19 & 233 & 280 & 0 & 25 & 255 & 0.434 \\
\hline Liu et al., (2012) & $\begin{array}{l}\text { Hepatocellular } \\
\text { carcinoma }\end{array}$ & China & Asian & TaqMan & Male & $\mathrm{HCC}$ & 500 & 315 & 169 & 16 & 590 & 399 & 173 & 18 & 0.886 \\
\hline
\end{tabular}

PCR-RFLP = polymerase chain reaction-restriction fragment length polymorphism; HCC $=$ hospital-based casecontrol; PCC = population-based case-control; HWE = Hardy-Weinberg equilibrium; NA = not applicable. ${ }^{a}=\mathrm{CG}+\mathrm{GG}$ is provided in this study.

\section{Overall analysis}

The association of rs 1800796 in the IL6 gene with cancer was investigated in 19 studies with a total of 9985 cases and 13,045 controls. As shown in Table 2, Table 3, Figure 2, Figure 3 and Figure 4, significant association was observed under three genetic models (allele $\mathrm{G}$ vs allele $\mathrm{C}$, pooled $\mathrm{OR}=1.182, \mathrm{P}=0.009 ; \mathrm{CG}+\mathrm{GG}$ vs $\mathrm{CC}$, pooled $\mathrm{OR}=1.333, \mathrm{P}=0.006 ; \mathrm{CG}$ vs CC, pooled $\mathrm{OR}=1.323, \mathrm{P}=0.007)$. Significant heterogeneity was also observed with $\mathrm{P}<0.1$. However, no significant association was observed in other genetic model in the overall analysis (Table 2).

\section{Subgroup analysis}

Results of subgroup meta-analysis and heterogeneity test are shown in Table 2 and Table 3.

When studies were stratified according to cancer types, the results indicated that rs 1800796 was significantly associated with prostate cancer under two genetic models (allele $\mathrm{G}$ vs allele $\mathrm{C}$, pooled $O R=1.324, P=0.023 ; G G$ vs $C G+C C$, pooled $O R=1.263, P=0.034)$. Neither significant heterogeneity $(P>0.1)$ nor significant association was observed in other genetic models. In other cancer types, no significant association was found between rs1800796 and cancer risk.

When studies were stratified according to the ethnicity of samples, the results showed that significant associations were observed in Asians under four genetic models (allele $G$ vs allele $C$, pooled $O R=1.258, P=0.006$; $C G+G G$ vs $C C$, pooled $O R=1.380, P=0.005 ; G G$ vs $C C$, pooled $\mathrm{OR}=1.465, \mathrm{P}=0.036$; $\mathrm{CG}$ vs $\mathrm{CC}$, pooled $\mathrm{OR}=1.35, \mathrm{P}=0.007$ ). However, significant heterogeneity was observed under all four genetic models with $\mathrm{P}<0.1$. There was no significant association observed in other ethnic subgroups. 


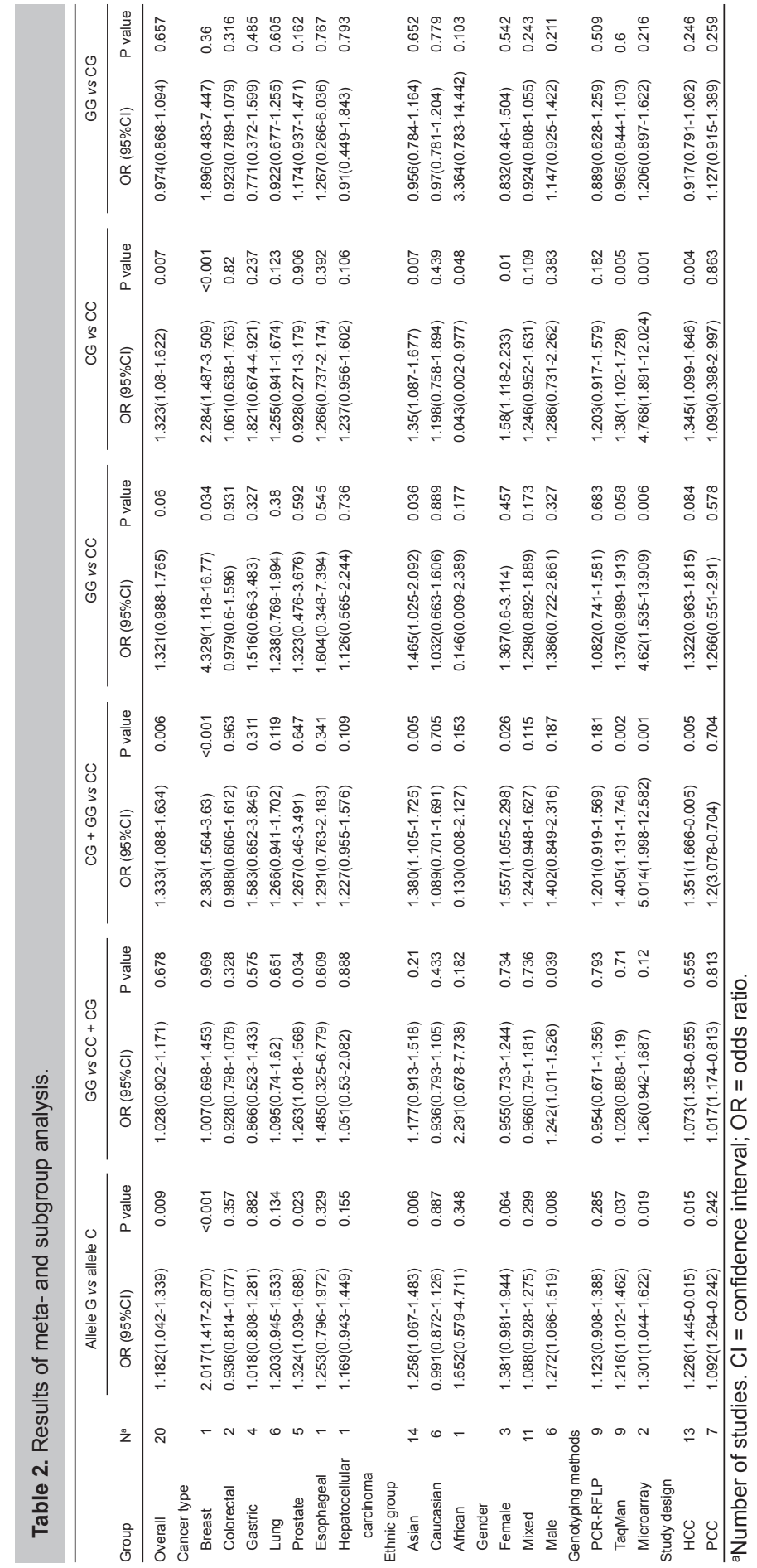


Table 3. Heterogeneity tests for each genotype in the overall and subgroup analysis.

\begin{tabular}{|c|c|c|c|c|c|c|c|c|c|c|c|c|c|}
\hline \multirow[b]{2}{*}{ Group } & \multirow[b]{2}{*}{$\mathrm{N}^{\mathrm{a}}$} & \multicolumn{2}{|c|}{ G vs C } & \multicolumn{2}{|c|}{$G G$ vs $C C+C G$} & \multicolumn{2}{|c|}{$\mathrm{CG}+\mathrm{GG}$ vs $\mathrm{CC}$} & \multicolumn{2}{|c|}{ GG vs CC } & \multicolumn{2}{|c|}{ CG vs CC } & \multicolumn{2}{|c|}{ GG vs CG } \\
\hline & & $P^{2}$ & $P$ value & $P^{2}$ & $P$ value & $l^{2}$ & $P$ value & $1^{2}$ & $P$ value & $1^{2}$ & $P$ value & $1^{2}$ & $P$ value \\
\hline Overall & 20 & $65.70 \%$ & $<0.001$ & $29.90 \%$ & 0.107 & $67.00 \%$ & $<0.001$ & $34.10 \%$ & 0.084 & $65.00 \%$ & $<0.001$ & $14.70 \%$ & 0.282 \\
\hline \multicolumn{14}{|l|}{ Cancer type } \\
\hline Breast & 1 & NA & NA & $69.30 \%$ & 0.039 & NA & NA & NA & NA & NA & NA & NA & NA \\
\hline Colorectal & 2 & NA & NA & NA & NA & NA & NA & NA & NA & NA & NA & NA & NA \\
\hline Gastric & 4 & $0.00 \%$ & 0.747 & $27.00 \%$ & 0.254 & $0.00 \%$ & 0.633 & $0.00 \%$ & 1 & $34.20 \%$ & 0.219 & $57.90 \%$ & 0.093 \\
\hline Lung & 6 & $81.60 \%$ & $<0.001$ & $50.70 \%$ & 0.071 & $81.60 \%$ & $<0.001$ & $65.00 \%$ & 0.014 & $78.50 \%$ & $<0.001$ & $22.10 \%$ & 0.268 \\
\hline Prostate & 5 & $0.00 \%$ & 0.601 & $0.00 \%$ & 0.494 & $40.40 \%$ & 0.169 & $38.30 \%$ & 0.182 & $51.70 \%$ & 0.102 & $5.20 \%$ & 0.367 \\
\hline Esophageal & 1 & NA & NA & NA & NA & NA & NA & NA & NA & NA & NA & NA & NA \\
\hline $\begin{array}{l}\text { Hepatocellular } \\
\text { carcinoma }\end{array}$ & 1 & NA & NA & NA & NA & NA & NA & NA & NA & NA & NA & NA & NA \\
\hline \multicolumn{14}{|l|}{ Ethnic group } \\
\hline Asian & 14 & $76.20 \%$ & $<0.001$ & $26.80 \%$ & 0.189 & $76.70 \%$ & $<0.001$ & $48.40 \%$ & 0.036 & $73.20 \%$ & $<0.001$ & $0.00 \%$ & 0.599 \\
\hline Caucasian & 6 & $0.60 \%$ & 0.403 & $44.70 \%$ & 0.107 & $0.00 \%$ & 0.558 & $0.00 \%$ & 0.568 & $0.00 \%$ & 0.471 & $45.00 \%$ & 0.122 \\
\hline African & 1 & NA & NA & NA & $\mathrm{NA}$ & NA & NA & NA & NA & NA & NA & NA & NA \\
\hline \multicolumn{14}{|l|}{ Gender } \\
\hline Female & 3 & $71.30 \%$ & 0.031 & $43.20 \%$ & 0.134 & $67.60 \%$ & 0.046 & $54.00 \%$ & 0.114 & $56.30 \%$ & 0.101 & $16.00 \%$ & 0.304 \\
\hline Mixed & 11 & $71.30 \%$ & 0.001 & $39.00 \%$ & 0.108 & $69.10 \%$ & 0.001 & $45.20 \%$ & 0.067 & $64.90 \%$ & 0.004 & $20.50 \%$ & 0.261 \\
\hline Male & 6 & $0.00 \%$ & 0.758 & $0.00 \%$ & 0.641 & $22.10 \%$ & 0.274 & $17.70 \%$ & 0.302 & $39.70 \%$ & 0.157 & $0.00 \%$ & 0.46 \\
\hline \multicolumn{14}{|l|}{$\begin{array}{l}\text { Genotyping } \\
\text { methods }\end{array}$} \\
\hline PCR-RFLP & 9 & $72.70 \%$ & $<0.001$ & $31.20 \%$ & 0.169 & $73.60 \%$ & $<0.001$ & $33.30 \%$ & 0.151 & $72.20 \%$ & $<0.001$ & $25.80 \%$ & 0.214 \\
\hline TaqMan & 9 & $15.10 \%$ & 0.315 & $18.20 \%$ & 0.281 & $21.70 \%$ & 0.264 & $1.90 \%$ & 0.41 & $34.90 \%$ & 0.162 & $0.00 \%$ & 0.604 \\
\hline Microarray & 2 & NA & NA & NA & NA & NA & NA & NA & NA & NA & NA & NA & NA \\
\hline \multicolumn{14}{|l|}{ Study design } \\
\hline $\mathrm{HCC}$ & 13 & $76.00 \%$ & $<0.001$ & $39.40 \%$ & 0.086 & $75.20 \%$ & $<0.001$ & $48.40 \%$ & 0.036 & $71.90 \%$ & $<0.001$ & $15.90 \%$ & 0.292 \\
\hline PCC & 7 & $0.00 \%$ & 0.469 & $21.20 \%$ & 0.261 & $0.60 \%$ & 0.412 & $0.00 \%$ & 0.43 & $18.80 \%$ & 0.291 & $0.00 \%$ & 0.538 \\
\hline
\end{tabular}

${ }^{\text {anumber of studies. }}$

\begin{tabular}{|c|c|c|c|}
\hline \multicolumn{2}{|l|}{ Study } & \multirow{3}{*}{$\begin{array}{l}\text { OR }(95 \% \mathrm{Cl}) \\
2.02(1.42,2.87)\end{array}$} & \multirow{3}{*}{$\begin{array}{l}\% \\
\text { Weight } \\
5.27\end{array}$} \\
\hline ID & & & \\
\hline $\mathrm{He}(2011)$ & $\longrightarrow$ & & \\
\hline Tsilidis (2009) & i & $0.86(0.50,1.48)$ & 3.39 \\
\hline Slattery (2007) & & $0.94(0.82,1.09)$ & 8.07 \\
\hline Tang (2007) & & $1.25(0.80,1.97)$ & 4.14 \\
\hline Hwang(1) (2003) & $\frac{1}{1}$ & $0.68(0.32,1.47)$ & 2.05 \\
\hline Hwang(2) (2003) & & $1.00(0.44,2.29)$ & 1.83 \\
\hline Xing (2006) & & $1.30(0.93,1.82)$ & 5.46 \\
\hline Kang (2009) & -1 & $0.92(0.71,1.20)$ & 6.45 \\
\hline Bai (2013) & $\perp$ & $1.51(1.11,2.06)$ & 5.83 \\
\hline Chen (2013) & i & $0.84(0.74,0.95)$ & 8.30 \\
\hline Liang (2013) & & $1.37(0.85,2.19)$ & 3.98 \\
\hline $\operatorname{Lim}(2011)$ & & $1.20(0.96,1.51)$ & 7.00 \\
\hline Seow (2006) & & $1.11(0.75,1.63)$ & 4.86 \\
\hline Kiyohara (2013) & & $1.45(1.14,1.83)$ & 6.85 \\
\hline Sun (2004) & I1 & $1.31(0.97,1.75)$ & 6.07 \\
\hline $\mathrm{Bao}(2008)$ & $\rightarrow$ & $1.81(1.27,2.59)$ & 5.22 \\
\hline Pierce(1) (2009) & & $0.93(0.57,1.51)$ & 3.85 \\
\hline Pierce(2) (2009) & & $\rightarrow 1.65(0.58,4.71)$ & 1.24 \\
\hline Wang (2009) & $\frac{1}{1}$ & $1.08(0.60,1.95)$ & 2.99 \\
\hline Liu $(2012)$ & $\rightarrow$ & $1.17(0.94,1.45)$ & 7.14 \\
\hline Overall $(\mathrm{I}-$ squared $=67.9 \%, p=0.000)$ & & $1.18(1.04,1.34)$ & 100.00 \\
\hline NOTE: Weights are from random effects analys & is & & \\
\hline $\begin{array}{lll}1 & 1 \\
212\end{array}$ & & 4.71 & \\
\hline
\end{tabular}

Figure 2. Forest plots of association between rs1800796 and cancer risk (allele G vs allele C). 


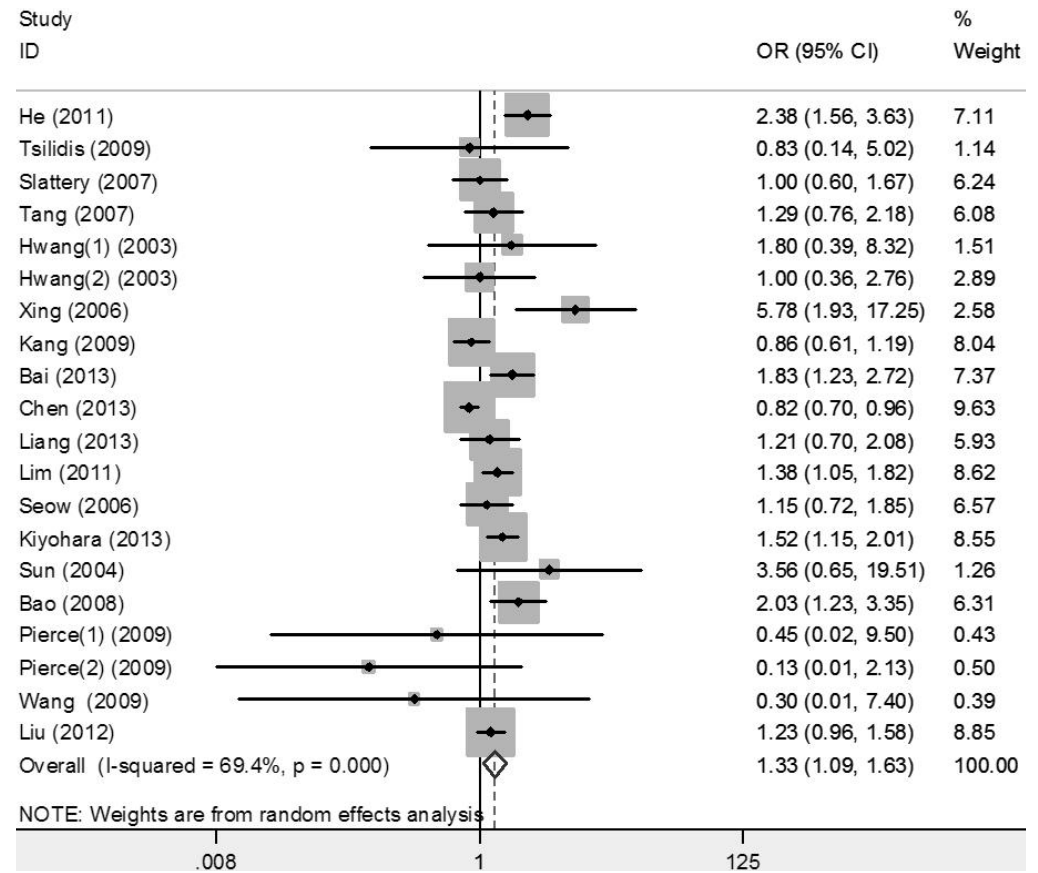

Figure 3. Forest plots of association between rs1800796 and cancer risk (CG + GG vs CC).

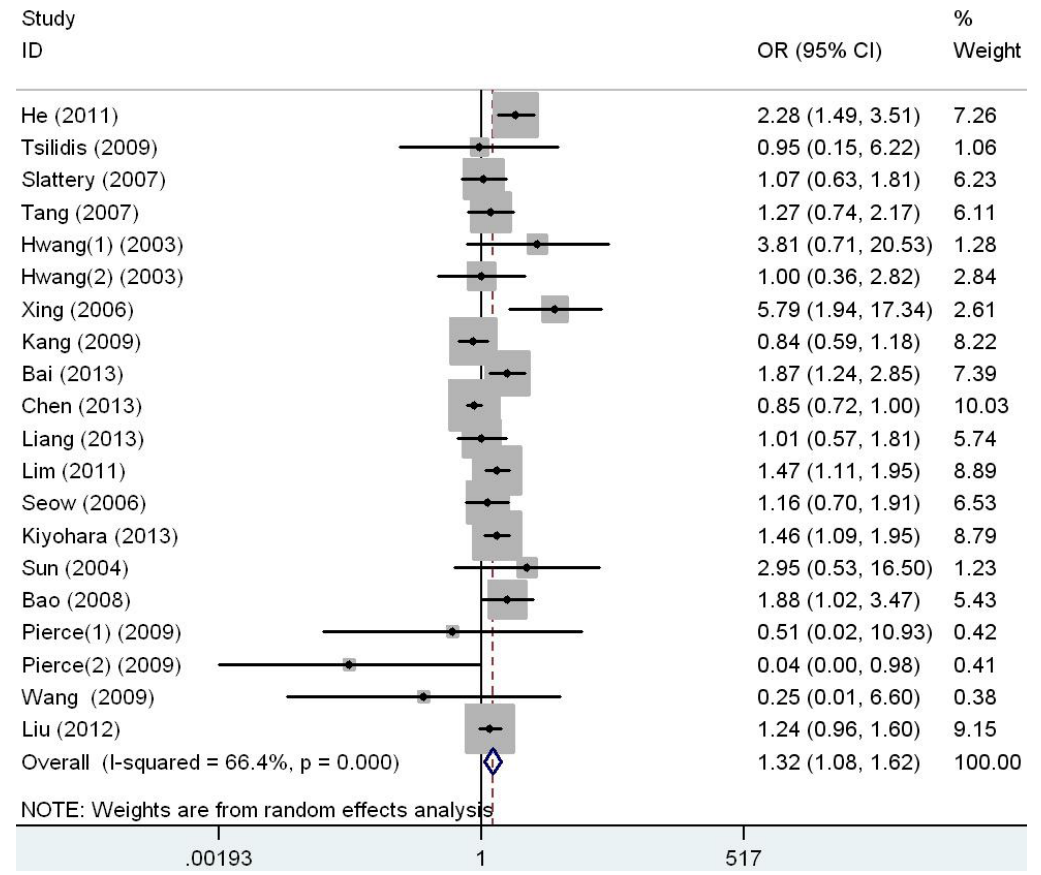

Figure 4. Forest plots of association between rs1800796 and cancer risk (CG vs CC). 
When studies were stratified according to gender of subjects, the results showed that significant associations were observed in both male (allele $\mathrm{G}$ vs allele $\mathrm{C}$, pooled $\mathrm{OR}=1.272, \mathrm{P}$ $=0.008$; $G G$ vs $C G+C C$, pooled $O R=1.242, P=0.039)$ and female samples $(C G+G G$ vs $C C$, pooled $\mathrm{OR}=1.557, \mathrm{P}=0.026 ; \mathrm{CG}$ vs $\mathrm{CC}$, pooled $\mathrm{OR}=1.58, \mathrm{P}=0.01$ ). No significant heterogeneity was observed in male samples $(P>0.1)$, while significant heterogeneity was observed in female samples with $(P<0.1)$. No significant association was observed in mixed samples.

When studies were stratified according to genotyping methods, significant associations were observed in both studies using Taqman technology (allele $\mathrm{G}$ vs allele $\mathrm{C}$, pooled OR $=1.216$, $P=0.037 ; C G+G G$ vs $C C$, pooled $O R=1.405, P=0.002 ; C G$ vs $C C$, pooled $O R=1.38, P=0.005$ ) and studies using microarray (allele $G$ vs allele $C$, pooled $O R=1.182, P=0.019 ; C G+G G$ vs $C C$, pooled $\mathrm{OR}=5.014, \mathrm{P}=0.001 ; \mathrm{GG}$ vs $\mathrm{CC}$, pooled $\mathrm{OR}=4.62, \mathrm{P}=0.006$; CG vs CC, pooled OR $=4.768, P=0.001$ ). No significant heterogeneity was observed with either microarray (all genetic models) or Taqman (dominant and recessive model) genotyping methods $(P>0.1)$. Lastly, no significant association was observed in studies using PCR-RFLP.

When studies were stratified according to study design, both significant associations and significant heterogeneity $(P<0.1)$ were observed in studies with hospital-based design (allele $G$ vs allele $\mathrm{C}$, pooled $\mathrm{OR}=1.226, \mathrm{P}=0.015 ; \mathrm{GG}$ vs $\mathrm{CG}+\mathrm{CC}$, pooled $\mathrm{OR}=1.351, \mathrm{P}=0.005 ; \mathrm{CG}$ vs $C C$, pooled $O R=1.345, P=0.004)$. However, no significant association was observed in studies with population-based design.

\section{Sensitivity analysis}

To determine whether a specific variable would affect the overall results, we compared the data before and after removing studies with significant deviation from the HWE (Slattery et al. 2007). It was determined that deviations from the HWE do not affect the overall analysis, which indicated that the results of the meta-analysis were not biased by studies with significant deviation from HWE (See Table S1 and Table S2). For subgroup analysis, removal of studies with significant deviation from HWE resulted in a loss of association rs1800796 and prostate cancer, while no significant difference was observed in other subgroup analyses (See Table S1 and Table S2).

\section{Publication bias}

Funnel plot and Egger's test were performed to assess the publication bias of the literature (See Fiqure S1). No significant publication bias was observed under all studied models (Allele $G$ vs allele $\mathrm{C}, \mathrm{P}=0.055 ; \mathrm{GG}$ vs $\mathrm{CG}+\mathrm{CC}, \mathrm{P}=0.085 ; \mathrm{GG}+\mathrm{CG}$ vs $\mathrm{CC}, \mathrm{P}=0.217$; GG vs CC, $\mathrm{P}=$ 0.148 ; $C G$ vs $C C, P=0.279 ; G G$ vs $C G, P=0.345)$.

\section{DISCUSSION}

Our meta-analysis demonstrated significant association between rs1800796 of IL6 and cancer risk, with the allele $\mathrm{G}$ as a risk allele. It has been previously reported that $\mathrm{rs} 1800796$ is associated with different levels of IL6 production (Fishman et al., 1998), and there are strong positive correlations between serum interleukin-6 concentrations and tumor size, tumor stage, or disease progression in various cancer patients (Lippitz, 2013). Our results supported previous studies, and indicated that individuals with genetic variants that give rise to reduced IL- 6 production 
may be at greater risk for cancer. $I L-6$ is involved in the recruitment of neutrophils, and promotes the migration and proliferation of T lymphocytes into the affected tissue (Romano et al., 1997). Findings also show that IL-6 provides a key signal during Th17 cell development, while blocking the differentiation of CD4+ cells into Treg cells (Bettelli et al., 2006). Increasing evidence suggest that the balance between Th17 and Treg cells may be involved in the development or progression of cancer (Chi et al., 2010). It is possible that the association of IL-6 with cancer risk may be due to modulation of Th17 and Treg differentiation.

In subgroup analysis, significant association was observed in Asians but not in Caucasian. In this study, a significant difference was observed in the frequency of allele G (rs1800796) between Asians (23.9\%) and Caucasians (93.8\%). The statistical power achieved in the Asian samples was 0.995 with the observed odds ratio of 1.258 and sample size of 8,173 ; however, due to different allele frequencies, when setting the odds ratio at 1.258, under the current sample size of 10,710 , the statistical power in the Caucasian samples was 0.758 . Under this allele frequency, the sample size required to gain sufficient statistical power (power $>0.9$ ) in Caucasians is 15,809 , indicating that insignificant association in the Caucasian population may be due to the limited sample size. Future studies with a sample size larger than 15,000 subjects are needed for further verification. Subgroup analysis using cancer types showed significant results only in prostate cancer, which is consistent with a previous study (Magalhaes et al., 2013). For individual cancers, sample size may still a limiting factor for statistical analysis.

Some limitations in this study are as follows: 1) in some cases, heterogeneity was still present after subgroup analysis, indicating that we were not able to detect all heterogeneous factors; 2) control subjects included in this study were not all subjected to the same study design. Controls from population-based studies and hospital-based studies might be under different psychical conditions, which might be a potential confounder; 3) this meta-analysis was based on unadjusted data, and a more precise analysis could be performed if individual data were available.

In conclusion, as the first meta-analysis investigating the association between rs1800796 of IL6 and overall cancer risk, our study observed that rs1800796 was significantly associated with cancer risk, with the allele $G$ as a risk allele, indicating that IL 6 may be a risk gene for cancer. Larger and well-designed studies based on different ethnic groups are needed to confirm our results.

\section{Supplementary material}

\section{REFERENCES}

Bai L, Yu H, Wang H, Su J, et al. (2013). Genetic single-nucleotide polymorphisms of inflammation-related factors associated with risk of lung cancer. Med. Oncol. 30: 414.

Bao S, Yang W, Zhou S and Ye Z (2008). Relationship between single nucleotide polymorphisms in -174G/C and -634C/G promoter region of interleukin-6 and prostate cancer. J. Huazhong Univ. Sci. Technol. Med. Sci. 28: 693-696.

Begg CB and Mazumdar M (1994). Operating characteristics of a rank correlation test for publication bias. Biometrics 50: 1088-1101.

Bettelli E, Carrier Y, Gao W, Korn T, et al. (2006). Reciprocal developmental pathways for the generation of pathogenic effector TH17 and regulatory T cells. Nature 441: 235-238.

Chen J, Liu RY, Yang L, Zhao J, et al. (2013). A two-SNP IL-6 promoter haplotype is associated with increased lung cancer risk. J. Cancer Res. Clin. Oncol. 139: 231-242.

Chi LJ, Lu HT, Li GL, Wang XM, et al. (2010). Involvement of T helper type 17 and regulatory T cell activity in tumour immunology of bladder carcinoma. Clin. Exp. Immunol. 161: 480-489.

Coussens LM and Werb Z (2002). Inflammation and cancer. Nature 420: 860-867. 
Fishman D, Faulds G, Jeffery R, Mohamed-Ali V, et al. (1998). The effect of novel polymorphisms in the interleukin-6 (IL-6) gene on IL-6 transcription and plasma IL-6 levels, and an association with systemic-onset juvenile chronic arthritis. $J$. Clin. Invest. 102: 1369-1376.

He KL, Li YP, Lv YG, Zhang DJ, et al. (2011). Association between polymorphisms of interleukin-6 gene promoter and breast cancer. Xi Bao Yu Fen Zi Mian Yi Xue Za Zhi 27: 1220-1222.

Higgins JP and Thompson SG (2002). Quantifying heterogeneity in a meta-analysis. Stat. Med. 21: 1539-1558.

Hwang IR, Hsu PI, Peterson LE, Gutierrez O, et al. (2003). Interleukin-6 genetic polymorphisms are not related to Helicobacter pylori-associated gastroduodenal diseases. Helicobacter 8: 142-148.

Kang JM, Kim N, Lee DH, Park JH, et al. (2009). The effects of genetic polymorphisms of IL-6, IL-8, and IL-10 on Helicobacter pylori-induced gastroduodenal diseases in Korea. J. Clin. Gastroenterol. 43: 420-428.

Kiyohara C, Horiuchi T, Takayama K and Nakanishi Y (2014). Genetic polymorphisms involved in the inflammatory response and lung cancer risk: A case-control study in Japan. Cytokine 65: 88-94.

Liang J, Liu X, Bi Z, Yin B, et al. (2013). Relationship between gene polymorphisms of two cytokine genes (TNF-alpha and IL-6) and occurring of lung cancers in the ethnic group Han of China. Mol. Biol. Rep. 40: 1541-1546.

Lim WY, Chen Y, Ali SM, Chuah KL, et al. (2011). Polymorphisms in inflammatory pathway genes, host factors and lung cancer risk in Chinese female never-smokers. Carcinogenesis 32: 522-529.

Lippitz BE (2013). Cytokine patterns in patients with cancer: a systematic review. Lancet Oncol. 14: e218-e228.

Liu RY, Song X, Chen P, Lei Z, et al. (2012). Association between IL6 -174G/C and cancer: A meta-analysis of 105,482 individuals. Exp. Ther. Med. 3: 655-664.

Liu S, Qiu XQ, Zeng XY, Bai H, et al. (2012). Relationship between IL6 -572G/C polymorphism and hepatocellular carcinoma in men. Zhonghua Gan Zang Bing Za Zhi 20: 463-467.

Lowry SF (1993). Cytokine mediators of immunity and inflammation. Arch. Surg. 128: 1235-1241.

Magalhães JF, Cortinhas AJ, Albuquerque CM, Baptista CS, et al (2013). Interleukin-6 gene -174G>C and -636G>C promoter polymorphisms and prostate cancer risk. Mol. Biol. Rep. 40: 449-455.

Moher D, Liberati A, Tetzlaff J, Altman DG, et al. (2009). Preferred reporting items for systematic reviews and meta-analyses: the PRISMA statement. PLoS Med. 6: e1000097.

Pierce BL, Biggs ML, DeCambre M, Reiner AP, et al. (2009). C-reactive protein, interleukin-6, and prostate cancer risk in men aged 65 years and older. Cancer Causes Contr. 20: 1193-1203.

Ray A, LaForge KS and Sehgal PB (1990). On the mechanism for efficient repression of the interleukin-6 promoter by glucocorticoids: enhancer, TATA box, and RNA start site (Inr motif) occlusion. Mol. Cell Biol. 10: 5736-5746.

Romano M, Sironi M, Toniatti C, Polentarutti N, et al (1997). Role of IL-6 and its soluble receptor in induction of chemokines and leukocyte recruitment. Immunity 6: 315-325.

Sagoo GS, Little J and Higgins JP (2009). Systematic reviews of genetic association studies. Human Genome Epidemiology Network. PLoS Med. 6: e28.

Seow A, Ng DP, Choo S, Eng P, et al. (2006). Joint effect of asthma/atopy and an IL-6 gene polymorphism on lung cancer risk among lifetime non-smoking Chinese women. Carcinogenesis 27: 1240-1244.

Slattery ML, Wolff RK, Herrick JS, Caan BJ, et al. (2007). IL6 genotypes and colon and rectal cancer. Cancer Causes Contr. 18: 1095-1105.

Slattery ML, Curtin K, Sweeney C, Wolff RK, et al. (2008). Modifying effects of IL-6 polymorphisms on body size-associated breast cancer risk. Obesity 16: 339-347.

Sun J, Hedelin M, Zheng SL, Adami HO, et al. (2004). Interleukin-6 sequence variants are not associated with prostate cancer risk. Cancer Epidemiol. Biomarkers Prev. 13: 1677-1679.

Tang RG, Wei YS, Chen HM, Fang WZ, et al. (2007). Serum level and genotype of interleukin-6 in patients with esophageal cancer. Zhonghua Yi Xue Za Zhi 87: 1126-1128.

Tsilidis KK, Helzlsouer KJ, Smith MW, Grinberg V, et al. (2009). Association of common polymorphisms in IL10, and in other genes related to inflammatory response and obesity with colorectal cancer. Cancer Causes Contr. 20: 1739-1751.

Verhagen M, van der Meij A, van Deurzen PA, Janzing JG, et al. (2010) Meta-analysis of the BDNF Val66Met polymorphism in major depressive disorder: effects of gender and ethnicity. Mol. Psychiatry 15: 260-271.

Wang MH, Helzlsouer KJ, Smith MW, Hoffman-Bolton JA, et al. (2009). Association of IL10 and other immune response- and obesity-related genes with prostate cancer in CLUE II. Prostate 69: 874-885.

Xing PX, Xiao DJ and Zeng QD. (2006). Relationship between cytokine gene polymorphisms on development and clinical characteristics of gastric adenocarcinoma. Chin. J. Gen. Surg. 15: 659-663.

Zintzaras E (2010). Impact of Hardy-Weinberg equilibrium deviation on allele-based risk effect of genetic association studies and meta-analysis. Eur. J. Epidemiol. 25: 553-560. 